\title{
Manejo da fertirrigação e controle da salinidade do solo sob ambiente protegido, utilizando-se extratores de solução do solo ${ }^{1}$
}

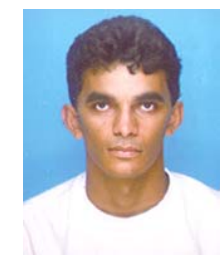

\author{
Nildo da S. Dias ${ }^{2}$, Sergio N. Duarte ${ }^{3}$, Hans R. Gheyi ${ }^{4}$, \\ José F. de Medeiros ${ }^{2} \&$ Tales M. Soares ${ }^{3}$
}

\begin{abstract}
1 Parte da Tese do primeiro autor apresentada a ESALQ/USP. Pesquisa financiada pela Fundação de Amparo à Pesquisa do Estado de São Paulo-FAPESP

2 UFERSA, Departamento de Ciências Ambientais, CP 137, CEP 59625-900, Mossoró, RN. Fone: (84) 33181762. E-mail: nildo@ufersa.edu.br (Foto)

${ }^{3}$ ESALQ/USP, LER, CP 09, CEP 13418-900, Piracicaba, SP. Fone: (019) 3429 4217. E-mail: snduarte@esalq.usp.br ${ }^{4}$ DEAg/UFCG. CP 10087, CEP 58109-970. Fone: (083) 310 1056. E-mail: hans@ufcg.edu.br
\end{abstract}

Protocolo $117-17 / 8 / 2004$ - Aprovado em 23/5/2005

\begin{abstract}
Resumo: Com o objetivo de avaliar o uso de extratores de soluções do solo no auxílio ao manejo da fertirrigação e no controle da salinidade em solo cultivado com melão rendilhado, conduziu-se um estudo em ambiente protegido na área experimental do Departamento de Engenharia Rural da ESALQ/USP, localizada no município de Piracicaba, SP. Os tratamentos se compunham da combinação de dois fatores: 6 níveis de salinidade inicial do solo $\left(S_{1}=1,0 ; S_{2}=2,0 ; S_{3}=\right.$ 3,$0 ; \mathrm{S}_{4}=4,0 ; \mathrm{S}_{5}=5,0$ e $\mathrm{S}_{6}=6,0 \mathrm{dS} \mathrm{m}^{-1}$ ) e dois manejos de fertirrigação: tradicional e com controle da condutividade elétrica da solução do solo. Procedeu-se à salinização inicial do solo por meio da aplicação de soluções salinas preparadas a partir de fertilizantes, em que a quantidade de sais a ser adicionada foi determinada tomando-se por base uma curva de salinização artificial, obtida previamente em laboratório. Os resultados mostraram que, com o uso de extratores de solução do solo, pode-se monitorar a concentração iônica da solução do solo, com precisão satisfatória. A salinidade do solo evoluiu com o tempo, estando os maiores níveis próximos à superfície do solo e do gotejador. A diferença no consumo de água entre os níveis de salinidade foi mais evidenciada no manejo controlado da fertirrigação, ajustando-se a um modelo quadrático.
\end{abstract}

Palavras-chave: condutividade elétrica, nutrição de plantas, Cucumis melo L

\section{Fertigation management and soil salinity control in a protected ambient using soil solution extractors}

\begin{abstract}
A study was carried out under greenhouse conditions at the experimental area of the Department of Rural Engineering of "Escola Superior de Agricultura Luiz de Queiroz-USP", Piracicaba, São Paulo state, Brazil, aiming to evaluate the performance of ceramic cup samplers in fertigation management and soil salinity control in a plot cultivated with netmelon. The treatments consisted of combination of two factors: six levels of initial soil salinity $\left(\mathrm{S}_{1}=1.0, \mathrm{~S}_{2}=2.0, \mathrm{~S}_{3}\right.$ $=3.0, \mathrm{~S}_{4}=4.0, \mathrm{~S}_{5}=5.0$ and $\mathrm{S}_{6}=6.0 \mathrm{dS} \mathrm{m}^{-1}$ ) and two fertigation management control: the traditional and the control of electrical conductivity of soil solution. The initial soil salinity value was obtained by applying saline solutions of fertilizer salts using an artificial soil salinization curve previously obtained in laboratory. Results showed that the solution extractors allow determination of the ionic concentration in soil solution with satisfactory accuracy. The soil salinity increased in time and higher salinity levels were observed near the soil surface and below the drippers. The differences in water consumption caused by soil salinity were more evident with fertigation management control, adjusting to a quadratic model.
\end{abstract}

Key words: electrical conductivity, plant nutrition, Cucumis melo L

\section{INTRODUÇÃO}

O cultivo em ambiente protegido proporciona diversas vantagens em relação ao cultivo tradicional, em campo aberto, como a proteção das plantas contra as adversidades climáticas, o aumento da produtividade, a maior eficiência na utilização de água e fertilizantes e a obtenção de produtos de alta qualidade comercial, mas o manejo inadequado da irrigação, a adição de 
fertilizantes em altas dosagens e a inexistência de chuvas promotoras de lixiviação do excesso de sais aplicados via água de irrigação, podem trazer, como conseqüência, a salinização dos solos, prejudicando o rendimento de culturas sensíveis como, por exemplo, a cultura do melão.

Observa-se também, embora em pequena intensidade, que a salinização pode provir da utilização de águas salinas oriundas de poços. Na região de Piracicaba, segundo Oliveira \& Salati (1981), é comum a ocorrência de poços tubulares profundos com águas ricas em cloretos e sulfatos de sódio, cujos teores podem propiciar uma condutividade elétrica (CE) às vezes superior a 3,0 dS m $\mathrm{m}^{-1}$ e com uma razão de adsorção de sódio capaz de causar toxidez, em virtude da absorção excessiva deste cátion.

Na maioria dos casos, entretanto, o aumento da salinidade em ambientes protegidos no Estado de São Paulo se dá em função do excesso de fertilizantes aplicados via água de irrigação. Assim, a utilização de uma estratégia de controle da salinidade por intermédio da aplicação de lâminas de lixiviação, recomendada por vários autores, como Hoorn \& Alphen (1981), por exemplo, não seria a prática de manejo mais adequada, visto que os sais acumulados no solo e que seriam lixiviados, foram adquiridos por investimento de capital (Silva et al., 1999).

Tradicionalmente, o manejo da fertirrigação é realizado ministrando-se quantidades preestabelecidas de fertilizantes, parceladas de acordo com a marcha de absorção da cultura não existindo, normalmente, monitoramento da concentração de íons na solução do solo nem do estado nutricional da planta (Papadopoulos, 1999); neste aspecto, seria mais indicado racionalizar o manejo da fertirrigação por meio da determinação da condutividade elétrica e/ou da concentração parcial de íons na solução do solo. Caso a condutividade elétrica da solução do solo apresentasse valores inferiores ao máximo tolerado pela cultura, sem decréscimo no rendimento relativo, e superiores ao mínimo necessário para sua nutrição, a salinização estará controlada (Burgueño, 1996).

A identificação dos solos afetados por sais se baseia em uma série de observações e estudos da área, incluindo-se a observação de características visuais de campo e a realização de diversas análises, tanto por métodos de laboratório como por métodos de campo. No laboratório, a salinidade do solo pode ser estimada a partir de medidas de condutividade elétrica do extrato de saturação $\left(\mathrm{CE}_{\mathrm{es}}\right)$ ou da condutividade elétrica (CE) em diferentes relações solo : água destilada (Richards, 1954); em campo, vários métodos são disponíveis para determinar a CE e avaliar a salinidade do solo, tais como a técnica de indução eletromagnética, o time domain reflectometry-TDR (Rhoades, 1994) e, ainda, mediante o uso de extratores de solução. Cada um desses métodos apresenta vantagens e desvantagens, sendo que o uso de extratores por cápsula porosa é, atualmente, um dos mais recomendados, tendo em vista a boa relação entre o custo e a precisão do método (Silva, 2002) e, também, devido ao fato de que a CE obtida por esse método reflete as condições reais em que a planta se desenvolve.

Considerando-se inevitável a ocorrência de desequilíbrios nutricionais, em virtude da dificuldade de se quantificar com precisão os nutrientes absorvidos pela planta e também à interferência inerente ao complexo de troca catiônica do sistema solo, estudos realizados por vários autores, como Silva (2002) por exemplo, propõem o monitoramento periódico da salinidade e de alguns nutrientes na solução do solo, com auxílio dos extratores de solução e de testes rápidos; deste modo objetivouse, com o presente trabalho, avaliar o uso de extratores de solução no auxílio ao manejo da fertirrigação e no monitoramento e controle da evolução da salinidade em solo sob condição protegida.

\section{MATERIAL E MÉTODOS}

O experimento foi conduzido em duas estufas plásticas do Departamento de Engenharia Rural da Escola Superior de Agricultura “Luiz de Queiroz"-USP, no município de Piracicaba, $\mathrm{SP}$, situado nas coordenadas geográficas $22^{\circ} 42^{\prime}$ de latitude sul e $47^{\circ} 38^{\prime}$ de longitude oeste, a uma altitude de $540 \mathrm{~m}$. O material de solo utilizado foi originado de um perfil classificado como Latossolo Vermelho fase arenosa, proveniente do campus da ESALQ e denominado Série "Sertãozinho", do qual se retiraram amostras da camada de 0-20 cm para as análises química (Tabela 1) e físico-hídricas (Tabela 2), realizadas no Departamento de Solos e Nutrição de Plantas da ESALQ/USP.

Os tratamentos foram formados da combinação de dois fatores: salinidade inicial do solo com 6 níveis $\left(\mathrm{S}_{1}=1,0 ; \mathrm{S}_{2}=\right.$ 2,$0 ; \mathrm{S}_{3}=3,0 ; \mathrm{S}_{4}=4,0 ; \mathrm{S}_{5}=5,0$ e $\mathrm{S}_{6}=6,0 \mathrm{dS} \mathrm{m}^{-1}$ ) e dois manejos de fertirrigação $\left(M_{1}=\right.$ tradicional e $M_{2}=$ com controle da concentração iônica da solução do solo). O delineamento estatístico adotado foi o de blocos casualizados completos com 4 repetições e os fatores estudados foram arranjados em esquema fatorial $6 \times 2$.

Tabela 1. Características química do solo

\begin{tabular}{|c|c|c|c|c|c|c|c|c|c|c|c|}
\hline \multirow{2}{*}{$\begin{array}{c}\text { Camada } \\
\mathrm{cm}\end{array}$} & \multirow{2}{*}{$\begin{array}{c}\mathrm{pH} \\
\left(\mathrm{CaCl}_{2}\right)\end{array}$} & \multirow{2}{*}{$\begin{array}{l}\mathrm{MO}^{*} \\
\mathrm{~g} \mathrm{~kg}^{-1}\end{array}$} & $P$ & $\mathrm{~S}$ & $\mathrm{~K}^{+}$ & $\mathrm{Ca}^{2+}$ & $\mathrm{Mg}^{2+}$ & $\mathrm{H}+\mathrm{Al}^{3+}$ & CTC & $\mathrm{V}$ & $\mathrm{m}$ \\
\hline & & & \multicolumn{2}{|c|}{$\mathrm{mg} \mathrm{dm}^{-3}$} & \multicolumn{5}{|c|}{$\mathrm{mmol}_{\mathrm{c}} \mathrm{dm}^{-3}$} & \multicolumn{2}{|c|}{$\%$} \\
\hline $0-20$ & 4,3 & 7 & 2 & 4 & 1,1 & 9 & 4 & 18 & 32,1 & 44 & 18 \\
\hline
\end{tabular}

Tabela 2. Características físico-hídricas do solo

\begin{tabular}{|c|c|c|c|c|c|c|c|c|}
\hline \multirow{2}{*}{$\begin{array}{c}\text { Camada } \\
\mathrm{cm}\end{array}$} & $C \Gamma$ & PMP & \multirow{2}{*}{ 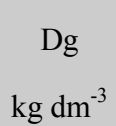 } & \multicolumn{3}{|c|}{ Frações Granulométricas } & Floculação & Textura \\
\hline & \multicolumn{2}{|c|}{$\mathrm{cm}^{3} \mathrm{~cm}^{-3}$} & & Argila & $\mathrm{g} \mathrm{kg}^{-1}$ & Areia & & 10 \\
\hline $0-20$ & 0,213 & 0,137 & 1,4 & 280 & 80 & 640 & 100 & Franco-arenosa \\
\hline
\end{tabular}


A salinização do solo foi realizada por meio da aplicação de soluções salinas, com a quantidade de sais a ser adicionada determinada pela curva de salinização artificial obtida por Dias et al. (2003), as proporções e os tipos de sal aplicado na água seguiram aqueles correspondentes à extração total de nutrientes para a cultura do melão rendilhado, conforme relatado por Kano (2002).

Os tratamentos se dispunham em 48 parcelas de 2,0 $\mathrm{m}^{2}(1,00$ $\mathrm{x} 2,00 \mathrm{~m}$ ) cada uma formada por uma fileira de plantas, espaçada $2,00 \mathrm{~m}$, com $0,30 \mathrm{~m}$ entre plantas, totalizando 7 plantas por fileira, dentre as quais apenas as 5 plantas centrais foram consideradas úteis e as demais plantas da parcela foram tidas como bordadura; os tratamentos foram isolados entre si, utilizando-se divisões subterrâneas, com $0,50 \mathrm{~m}$ de profundidade, constituídas de filme de polietileno, para evitar possíveis contaminações entre os tratamentos (Figura 1).

A.

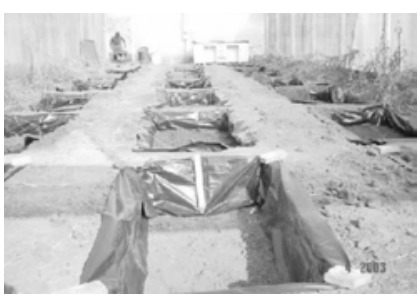

B.

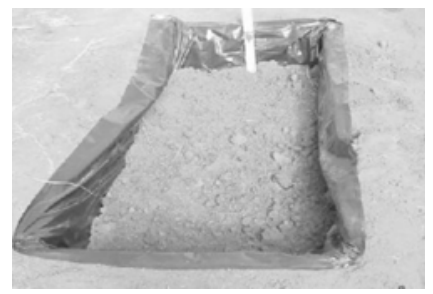

Figura 1. Construção das parcelas experimentais isoladas, utilizando-se divisões subterrâneas, com filme de polietileno (A) e detalhe da construção de uma parcela experimental (B)

A cultura utilizada foi o melão rendilhado (Cucumis melo L.), cultivar Bônus II, em dois plantios consecutivos no mesmo par de estufas, o primeiro transplantado no dia 5 de julho e o segundo em 3 de dezembro de 2003, cujas colheitas perfaziam um ciclo de 117 e 94 dias, respectivamente. Ressalta-se que entre o final do primeiro ciclo e o início do segundo, transcorreram 35 dias.

Adotou-se um sistema de irrigação por gotejamento, utilizando-se emissores do tipo autocompensante, com vazão nominal de 4,0 $\mathrm{L} \mathrm{h}^{-1}$, previamente avaliados em campo sob condições normais de operação, apresentando um coeficiente de variação de vazão de $6,33 \%$, uniformidade de distribuição de $94,89 \%$ e vazão média real de $3,95 \mathrm{~L} \mathrm{~h}^{-1}$. Os gotejadores estavam acoplados às linhas de tubo de polietileno, no início das quais foram instalados registros, o que possibilitou aplicarse o volume diferenciado de água. As parcelas com tratamentos $\mathrm{M}_{2}$ possuíam duas linhas de gotejadores, uma para aplicar solução de fertirrigação e outra para aplicar apenas água, quando a aplicação de fertilizantes não se fazia necessária, evitando possível contaminação.

Quanto ao manejo de irrigação, baseou-se em dados de umidade do solo, obtidos de tensiômetros instalados a 0,20 e $0,40 \mathrm{~m}$ de profundidade e de uma curva característica de retenção de água no solo, obtida por Silva (2002). Estabeleceu-se um turno de rega fixo de 2 dias e se usou a tensão média no tensiômetro a $0,20 \mathrm{~m}$ para se definir a quantidade de água a ser aplicada, suficiente para elevar o conteúdo de água do volume de solo úmido à capacidade de campo. $\mathrm{O}$ volume de água aplicado foi calculado a partir da curva característica de retenção da água no solo e das médias das leituras tensiométricas, para cada nível de salinidade.

A aplicação dos fertilizantes foi realizada via água de irrigação, sendo o manejo diferenciado para os tratamentos $\mathrm{M}_{1}$ e $M_{2}$; para o tratamento $M_{1}$, utilizaram-se as recomendações propostas por Kano (2002), tendo em vista a marcha de absorção da cultura. A freqüência da fertirrigação para este tratamento seguiu a mesma freqüência da irrigação. Para o tratamento referente ao manejo $\mathrm{M}_{2}$ empregou-se, inicialmente, a mesma recomendação do manejo $M_{1}$ porém, a partir de 8 dias após o transplantio (DAT), não foi preestabelecida a freqüência nem a proporção dos fertilizantes aplicados neste manejo. A fertirrigação só foi realizada quando a condutividade elétrica na solução do solo estava em média $20 \%$ abaixo dos níveis iniciais de salinização do solo para cada tratamento, sendo esta cessada quando a condutividade se encontrava, em média, $20 \%$ acima dos mesmos níveis iniciais; desta forma, a concentração iônica total na solução do solo controlou o manejo da fertirrigação. Foram utilizados como fontes de fertilizantes, os seguintes produtos: nitrato de amônio, cloreto de potássio, sulfato de magnésio, acido fosfórico e nitrato de cálcio.

A condutividade elétrica da solução do solo foi medida após o término de cada evento de irrigação utilizando-se, para extração, cápsulas porosas sob vácuo, enquanto para a obtenção do extrato se retirava o ar de dentro dos extratores, introduzindo-se uma agulha na borracha especial de vedação, acoplada a uma seringa de $60 \mathrm{~mL}$, ou por meio de uma bomba de vácuo, criando uma sucção interna de aproximadamente $80 \mathrm{kPa}$. A aplicação do vácuo aos extratores se deu $12 \mathrm{~h}$ após a irrigação, momento em que era verificada a umidade do solo, por meio de tensiometria. As cápsulas dos extratores e dos tensiômetros foram instaladas no centro de cada parcela, localizadas opostamente uma à outra, a uma profundidade de $0,20 \mathrm{~m}$ da superfície do solo e a uma distância de $0,10 \mathrm{~m}$ da planta.

Os valores de condutividade elétrica, medidos na solução retirada a partir dos extratores de cápsula porosa a diferentes umidades do solo, foram comparados com os valores obtidos pelo método padrão, ou seja, pela medição da condutividade elétrica no extrato da pasta saturada e corrigidos os valores de leitura de condutividade elétrica da solução em função da umidade de saturação, a partir da Eq. 1:

$$
\mathrm{CE}_{\mathrm{es}}=\mathrm{CE}_{\mathrm{s}} \frac{\mathrm{Ua}}{\mathrm{Us}}
$$

em que:

$\mathrm{CE}_{\mathrm{es}}$ - condutividade elétrica no extrato de saturação estimada, $\mathrm{dS} \mathrm{m}^{-1}$

$\mathrm{CE}_{\mathrm{s}}$ - condutividade elétrica na solução do solo obtida com extrator de solução, $\mathrm{dS} \mathrm{m}^{-1}$

$\mathrm{U}_{\mathrm{a}} \quad$ - umidade atual do solo durante o tempo de coleta da solução, $\mathrm{g} \mathrm{g}^{-1}$

$\mathrm{U}_{\mathrm{s}}$ - umidade do solo na pasta saturada, $\mathrm{g} \mathrm{g}^{-1}$

Avaliou-se o potencial mátrico médio durante o ciclo da cultura, monitorado diariamente por tensiômetros instalados a 
0,20 e 0,40 m da superfície do solo. Para se determinar o perfil transversal de salinidade do solo durante o ciclo da cultura, foram retiradas amostras ao longo do ciclo do melão, à esquerda e à direita do gotejador, isto é, coletadas a cada $0,15,30$ e $45 \mathrm{~cm}$ para ambos os lados, nas camadas de $0-15,15-30$ e $30-45 \mathrm{~cm}$, aos 60 e 90 dias após o transplantio (DAT). A condutividade elétrica do extrato de saturação $\left(\mathrm{CE}_{\mathrm{es}}\right)$ dessas amostras foi estimada com base em regressão a partir da $\mathrm{CE}_{1: 2}$, medida no sobrenadante da mistura de uma parte de solo, para duas de água destilada (Medeiros, 1998). A partir dos dados de $\mathrm{CE}_{\mathrm{es}}$ foram traçados as curvas de evolução da salinidade ao longo do ciclo do meloeiro e os perfis de salinidade.

\section{RESULTADOS E DISCUSSÃO}

\section{Monitoramento da salinidade do solo}

Observa-se, na Figura 2, um ajuste razoável $\left(R^{2}=0,62\right)$ entre os valores de condutividade elétrica medidos no extrato de saturação e estimados a partir da condutividade elétrica da solução $\left(\mathrm{CE}_{\mathrm{s}}\right)$, obtida com extratores de cápsula porosa, com correção em função da umidade. Nota-se que o valor de $\mathrm{CE}_{\mathrm{es}}$ estimado pelas leituras de $\mathrm{CE}_{\mathrm{s}}$, com umidade corrigida, superou a condutividade elétrica do extrato de saturação medida em média 5,55 \% ( $<<0,01)$. A utilização do método de medição da condutividade elétrica da solução a partir de extrator de cápsula porosa é eficiente, devido à sua facilidade, versatilidade e praticidade, quando comparado com o da solução diluída 1:2, desde que sejam conhecidas a umidade da pasta saturada e a umidade no momento da extração. Silva et al. (1999) verificaram que a $\mathrm{CE}$ obtida por extratores corrigidos para umidade de saturação, equivale relativamente bem à $\mathrm{CE}$ do extrato de saturação medida pelo método padrão (Richards, 1954).

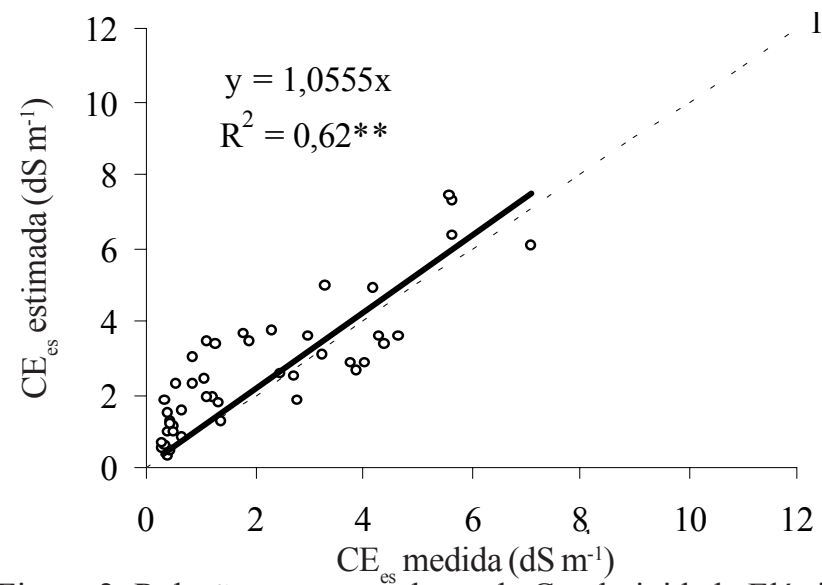

Figura 2. Relação entre os valores de Condutividade Elétrica do Extrato de Saturação ( $\left.\mathrm{CE}_{\mathrm{es}}\right)$ medida e estimada a partir da Condutividade Elétrica da Solução do Solo $\left(\mathrm{CE}_{\mathrm{s}}\right)$ obtida com extratores de cápsula porosa, com correção em função da umidade

Tem-se, na Figura 3, os valores de condutividade elétrica do extrato de saturação do solo, estimados por meio da correção dos valores de CE da solução extraída nas cápsulas porosas instaladas a $20 \mathrm{~cm}$ de profundidade, para os dois manejos da fertirrigação, ao longo dos dois ciclos consecutivos do meloeiro.
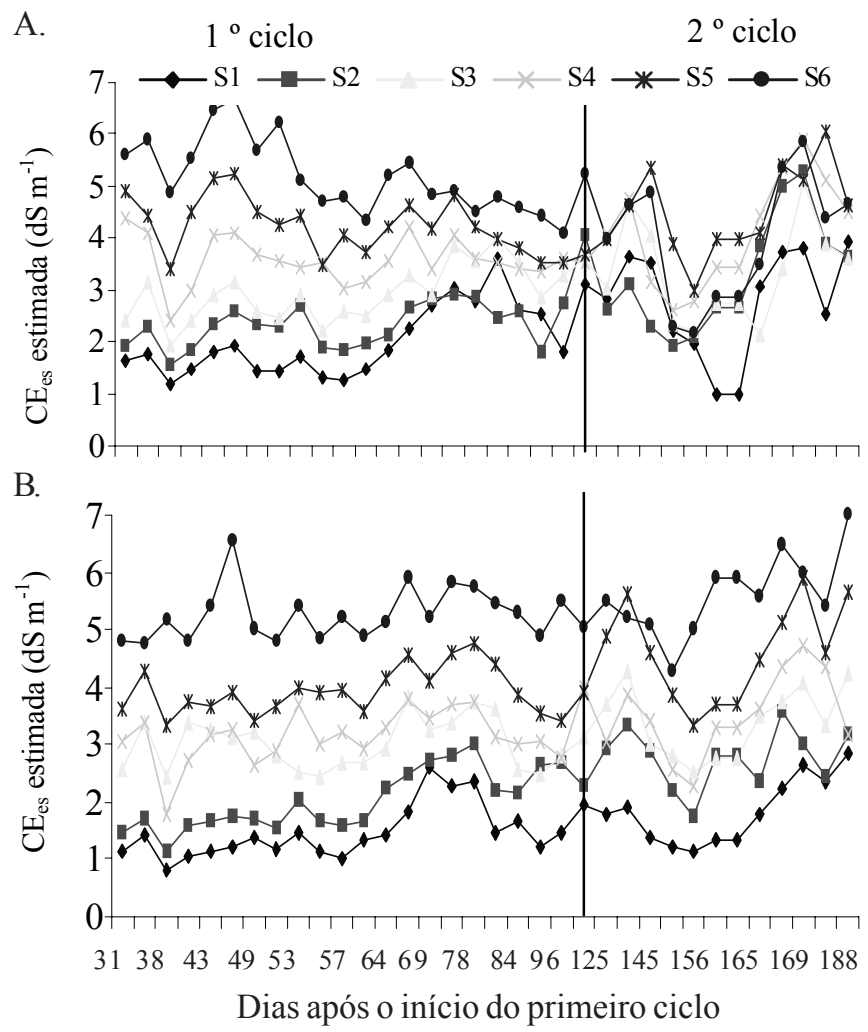

Figura 3. Valores de condutividade elétrica do extrato de saturação do solo a $0,20 \mathrm{~m}$, estimados a partir dos valores medidos na solução obtida por extratores, ao longo dos dois ciclos do meloeiro, para os dois manejos da fertirrigação propostos: manejo tradicional-M $\mathrm{M}_{1}$ (A) e manejo controlado$\mathrm{M}_{2}(\mathrm{~B})$

No primeiro ciclo, nota-se que no manejo da fertirrigação tradicional ocorre aumento da salinidade do solo para os tratamentos de níveis mais baixos $\left(\mathrm{S}_{1}, \mathrm{~S}_{2}\right.$ e $\left.\mathrm{S}_{3}\right)$ e decréscimo da salinidade para os níveis mais elevados $\left(\mathrm{S}_{4}, \mathrm{~S}_{5}\right.$ e $\left.\mathrm{S}_{6}\right)$, com tendência de equilíbrio no final do primeiro ciclo e durante o segundo ciclo. Esta tendência de equilíbrio dos sais se dá em razão de que apenas parte dos sais fertilizantes incorporados via água de irrigação, fica no solo, sendo uma parte absorvida pelas plantas para atender às suas necessidades enquanto outra se torna insolúvel, mediante a precipitação, quer por reações químicas ou pelo fato de atingir limites de solubilidade na solução do solo; além disso, outra parte, embora em quantidade pequena, pode ser eliminada por percolação, através da aplicação não intencional de eventuais lâminas de irrigação excessivas.

Por outro lado verifica-se, no manejo controlado, uma orientação com menor número de cruzamento de curvas dos níveis de salinidade, que se mantêm aproximadamente constantes ao longo dos dois ciclos. A manutenção dos níveis iniciais de salinidade ao longo dos dois ciclos do meloeiro, ocorreu devido ao bem sucedido monitoramento e à correção da condutividade elétrica da solução do solo, com base nos resultados com os extratores.

De acordo com Padilla (1998) se os problemas de salinidade criados pelo manejo inadequado dos fertilizantes forem a causa da redução do rendimento da cultura, deve-se corrigi-los antes 
de se empregar algum outro esforço físico ou econômico; neste caso, a evolução da salinidade do solo pode ser impedida com o monitoramento da condutividade elétrica e com a correção das quantidades aplicadas de fertilizantes; assim, fica evidenciado que o monitoramento da condutividade elétrica da solução do solo extraída por cápsulas porosas, permite evitarse possíveis processos de salinização e/ou de deficiência nutricional (Silva, 2002).

\section{Estimativa da $\mathrm{CE}_{\mathrm{es}}$ a partir da $\mathrm{CE}_{1: 2}$}

A estimativa da $\mathrm{CE}_{1: 2}$ (solo : água destilada) tem a vantagem de ser rápida, ter custos relativamente reduzidos e não precisar de equipamentos para retirar o extrato do solo, porém apresenta o inconveniente de necessitar do preestabelecimento da relação entre a $\mathrm{CE}_{\mathrm{es}}$ e a $\mathrm{CE}_{1: 2}$. De acordo com Rhoades \& Miyamoto (1990) a troca catiônica, a composição e a concentração total dos sais, a hidrólise, a dissolução mineral e as características de retenção de umidade do solo, podem afetar essas relações, o que representaria, sem dúvida, um problema na utilização dos extratos diluídos.

A Figura 4A mostra a relação entre a $\mathrm{CE}_{\mathrm{es}}$ e $\mathrm{CE}_{1: 2}$, seu coeficiente de determinação e sua equação, encontrados para as amostras do solo estudado. A equação que relaciona a $\mathrm{CE}_{\mathrm{es}}$ estimada por meio de soluções mais diluídas encontrada foi $\mathrm{CE}_{\mathrm{es}}=4,4519 \mathrm{CE}_{1: 2}+0,0242\left(\mathrm{R}^{2}=0,9129\right)$, podendo a $\mathrm{CE}_{1: 2}$ ser utilizada com boa precisão para estimar a $\mathrm{CE}_{\mathrm{es}}$, uma vez que existe alta correlação. Segundo Medeiros et al. (1996) é comum

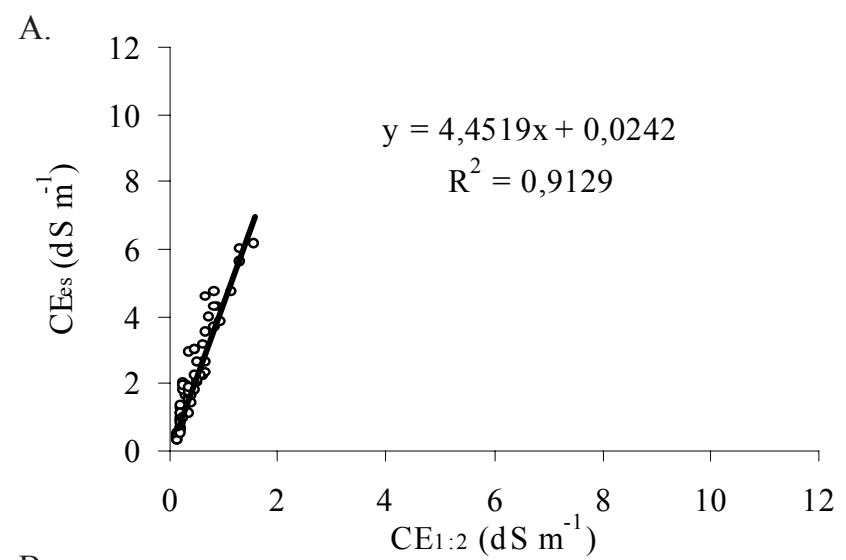

B.

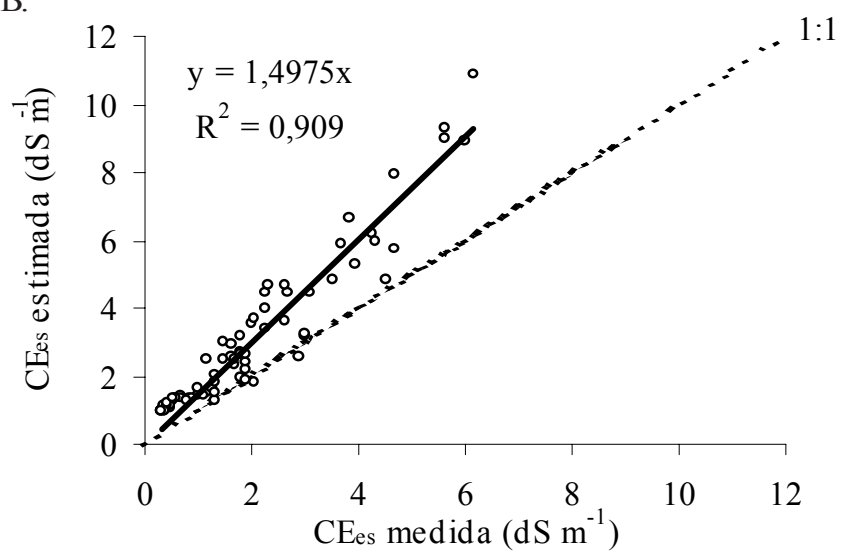

Figura 4. Relação entre a $\mathrm{CE}_{\mathrm{es}}$ e $\mathrm{CE}_{1: 2}(\mathrm{~A})$ e a relação entre os valores $\mathrm{CE}_{\mathrm{es}}$, medidos e estimados a partir $\mathrm{CE}_{1: 2,}$, com correção em função da umidade de cada método (B) encontrar-se coeficiente de determinação acima de 0,90 para a relação entre $\mathrm{CE}_{1: 2}$ e $\mathrm{CE}_{\mathrm{es}}$. Filgueira \& Souto (1995) também verificaram a possibilidade de se utilizar extratos obtidos em relações 1:1 e 1:5, em substituição ao extrato de saturação, em solos salino-sódicos e sódicos degradados, da região de Patos, no Estado da Paraíba.

A Figura 4B indica a relação entre a condutividade elétrica do extrato de saturação medida e a estimada a partir $\mathrm{CE}_{1: 2}$, com correção em função dos diferentes valores de umidade obtidos em cada método. Verifica-se que a $\mathrm{CE}_{\mathrm{es}}$ estimada a partir da solução diluída $\left(\mathrm{CE}_{1: 2}\right)$, com umidade corrigida, superou a condutividade elétrica do extrato de saturação medida, principalmente para os valores mais elevados de CE. Conforme Hoorn \& Alphen (1994), o coeficiente linear da reta apresentado na Figura 4B, sensivelmente maior que $1(\mathrm{a}=1,4975)$ representa o incremento de $\mathrm{CE}$ da solução no extrato $1: 2$ devido à solubilidade de sais precipitados ao se adicionar maior volume de água nas soluções diluídas, o que constitui uma desvantagem do método. De acordo com Richards (1954) a segurança nas determinações de soluções mais diluídas depende das características do solo e do tipo de sais presentes, pois sais de baixa solubilidade precipitados no solo podem ser dissolvidos em proporções maiores que no extrato de saturação, em virtude da adição de água destilada e, conseqüentemente, resultar em superestimativa dos riscos de salinidade.

\section{Evolução da salinidade do solo na zona radicular do meloeiro}

O acúmulo de sais no solo depende da qualidade da água de irrigação, das propriedades físicas do solo e, sobretudo, das condições de drenagem e do balanço de água e de sais no subsolo. Segundo Daker (1984) ligeiras diferenças na textura do solo podem provocar uma distribuição desigual de água nas camadas do solo, acarretando desuniformidade na acumulação de sais, ao longo do perfil.

Nas Figuras 5 e 6 observa-se a distribuição das concentrações de sais $\left(\mathrm{CE}_{\mathrm{es}}\right.$ estimada a partir da $\left.\mathrm{CE}_{1: 2}\right)$ no perfil do solo aos 60 e 90 DAT do primeiro ciclo do meloeiro, em parcelas com níveis de salinidade $\mathrm{S}_{1}, \mathrm{~S}_{3}$ e $\mathrm{S}_{6}$, para os dois manejos da fertirrigação $\left(M_{1}\right.$ e $\left.M_{2}\right)$. Verifica-se, nos níveis de salinidade $\mathrm{S}_{1}$ e $\mathrm{S}_{3}$, que as maiores concentrações de sais ocorreram na região próxima à superfície do solo e sob o gotejador, diminuindo com profundidade, acarretando a formação de isolinhas salinas bem definidas. Tal fato pode ser atribuído à alta freqüência de fertirrigação e à maior evaporação e extração de água pelas plantas na camada superficial e perto do gotejador, como citam Hoffman et al. (1992). De acordo com Khan et al. (1996) a distribuição de solutos no solo aplicados via fertirrigação por gotejamento, não acompanha exatamente a frente de avanço vertical da água, sendo que esta se movimenta um pouco à frente dos solutos, o que pode resultar no acúmulo de sais na zona radicular.

Para os perfis referentes ao tratamento de maior nível de salinidade $\left(\mathrm{S}_{6}\right)$, verificou-se acúmulo de sais nas camadas mais profundas devido, possivelmente, à lixiviação dos sais nesta camada e/ou solubilização dos sais precipitados durante o processo de salinização artificial no preparo da solução 1:2.

A evolução dos perfis indicou haver alargamento do bulbo com o tempo, com a salinidade aumentando para a periferia, sobretudo para o lado onde esteve localizada a planta, conforme 
A.

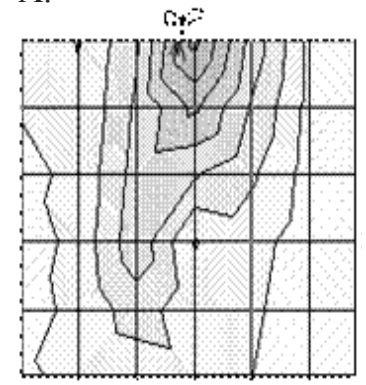

B.

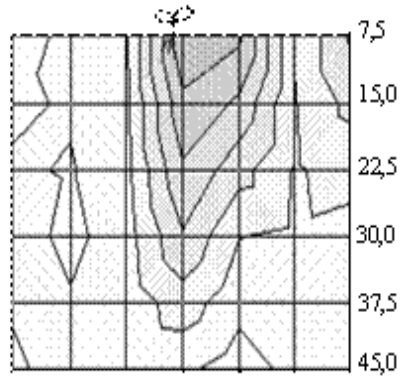

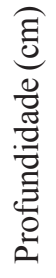

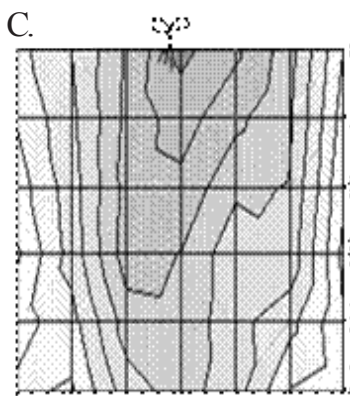

E.
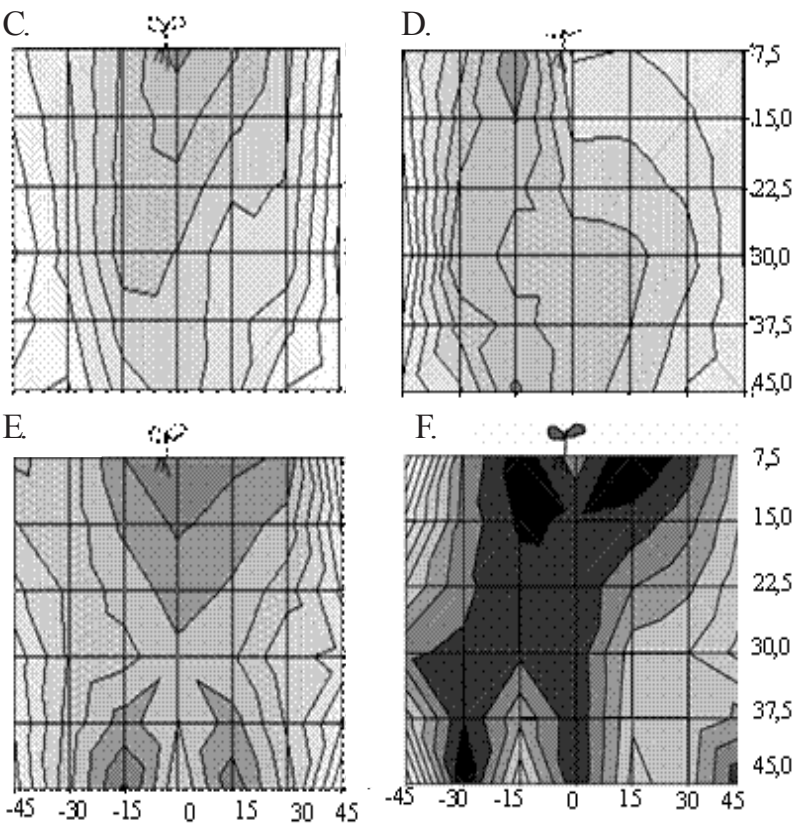

Distância transversal gotejador $(\mathrm{cm})$

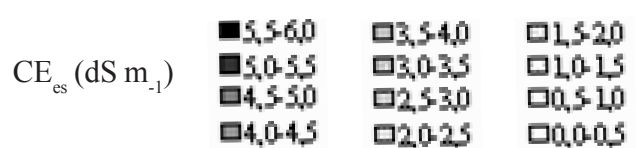

Figura 5. Perfis transversais de salinidade do solo, medidos aos 60 DAT do $1^{\circ}$ ciclo, para os tratamentos $\mathrm{S}_{1} \mathrm{M}_{1}$ (A), $\mathrm{S}_{1} \mathrm{M}_{2}$ (B), $\mathrm{S}_{3} \mathrm{M}_{1}(\mathrm{C}), \mathrm{S}_{3} \mathrm{M}_{2}(\mathrm{D}), \mathrm{S}_{6} \mathrm{M}_{1}(\mathrm{E}), \mathrm{S}_{6} \mathrm{M}_{2}(\mathrm{~F})$

verificado aos 90 DAT do primeiro ciclo, devido à ascensão e ao movimento lateral da solução salina, logo após a infiltração da água de irrigação na área central do bulbo, seguida da evaporação pela superfície do solo e extração de água pelas plantas, sendo a concentração de sais diretamente proporcional ao volume de água removido. De acordo com Ayers \& Westcot (1991), após se atingir o equilíbrio, a concentração de sais aumenta nas camadas mais profundas pelo fato da água de irrigação evapotranspirada pela cultura deixar os sais na zona radicular para serem deslocados por irrigações subseqüentes para sua parte inferior, onde se acumulam até serem lixiviados a maiores profundidades.

Com relação ao manejo da fertirrigação, verifica-se que, no nível de salinidade $\mathrm{S}_{1}$ do manejo controlado, foi menor a variação de CE no perfil do solo quando comparada com o manejo tradicional em razão, provavelmente devido a menor quantidade de fertilizantes aplicados via água de irrigação para se manter a salinidade desejada. De modo contrário, a variação
A.

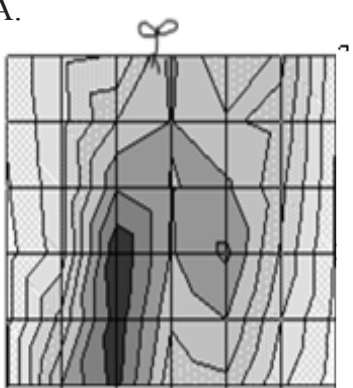

C.

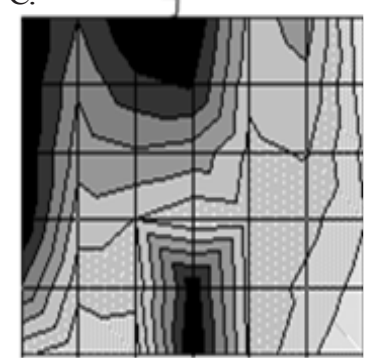

E.

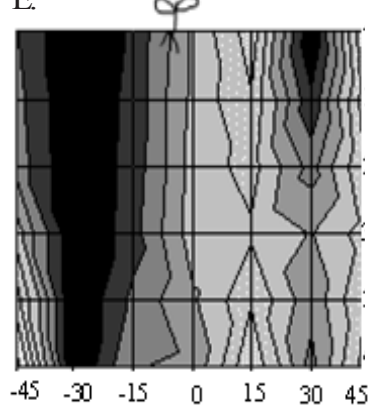

B.
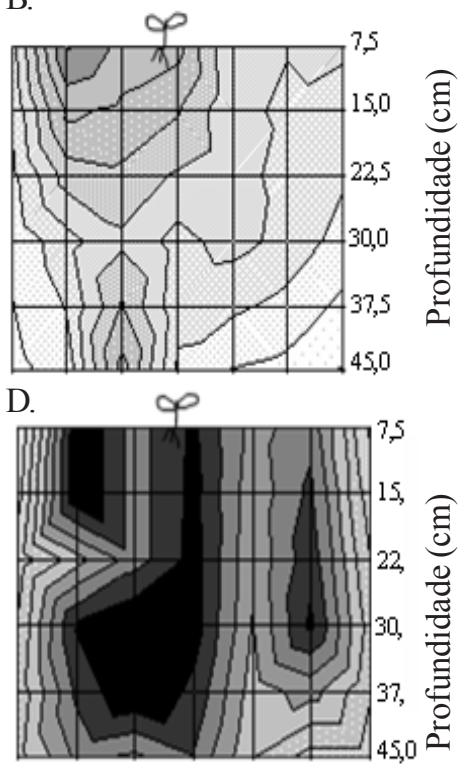

F.

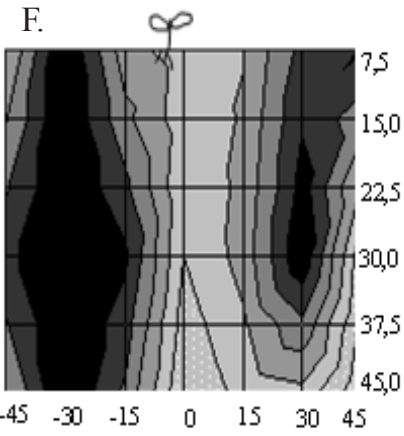

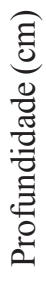

Distância transversal gotejador $(\mathrm{cm})$

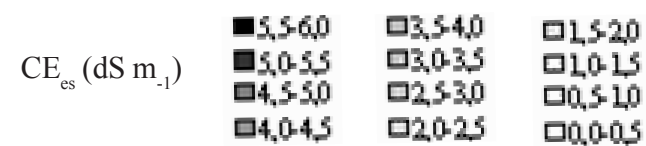

Figura 6. Perfis transversais de salinidade do solo, medidos aos 60 DAT do $2^{\circ}$ ciclo, para os tratamentos: $\mathrm{S}_{1} \mathrm{M}_{1}$ (A), $\mathrm{S}_{1} \mathrm{M}_{2}$ (B), $\mathrm{S}_{3} \mathrm{M}_{1}(\mathrm{C}), \mathrm{S}_{3} \mathrm{M}_{2}$ (D), $\mathrm{S}_{6} \mathrm{M}_{1}$ (E), $\mathrm{S}_{6} \mathrm{M}_{2}$ (F)

nos níveis de salinidade $\mathrm{S}_{3}$ e $\mathrm{S}_{6}$ do manejo controlado foi sempre maior, pelo fato dos adubos aplicados para corrigir a $\mathrm{CE}$ terem contribuído para elevar a salinidade do solo, sobretudo na periferia do bulbo.

\section{Potencial mátrico da água no solo}

Em solos salinos, o potencial osmótico é reduzido, resultando em menor absorção de água pelas plantas em decorrência da redução do potencial total da água no solo. Em conseqüência do menor consumo de água, ao se adotar um turno de rega fixo espera-se uma variação menor na umidade do solo, a qual pode ser monitorada pela medição do potencial mátrico $\left(\phi_{\mathrm{m}}\right)$ de vez que este potencial descreve a contribuição das forças de retenção da solução no solo, associadas às suas interfaces líquido-ar e sólido-líquido.

Os valores dos módulos do potencial mátrico $\left(\left|\phi_{\mathrm{m}}\right|\right)$, medidos no bulbo úmido a $20 \mathrm{~cm}$ de profundidade para os diferentes níveis de salinidade inicial do solo e manejos da fertirrigação, 
ao longo do primeiro ciclo do meloeiro, são mostrados na Figura 7 , na qual se observa maiores valores do $\left|\phi_{\mathrm{m}}\right|$ nos níveis de menor salinidade, com grande variação entre as irrigações consecutivas, em particular na fase de florescimento e frutificação (a partir de $74 \mathrm{DAT}$ ). É comum a redução do consumo de água pelas plantas, quando ocorrem maiores níveis de salinidade, em razão dos efeitos negativos do potencial osmótico, acarretando pequenas variações nos valores do $\left|\phi_{\mathrm{m}}\right|$, o que indica baixa variação da umidade do solo.

As médias do $\left|\phi_{\mathrm{m}}\right|$ ao longo do ciclo variaram de 93 a 129 cm.c.a. para os tratamentos $\mathrm{S}_{6} \mathrm{M}_{2}$ e $\mathrm{S}_{1} \mathrm{M}_{2}$, respectivamente, o que corrobora com os resultados verificados por Medeiros (1998), Blanco (1999) e Dias (2001), os quais demonstraram que os valores do módulo do potencial mátrico foram menores a medida em que se aumentou a salinidade do solo, indicando baixa variação da umidade; entretanto, quando se comparam os dois tipos do manejo da fertirrigação, vê-se que não houve diferença sensível da variação do módulo do potencial mátrico entre os mesmos.

Os maiores valores do $\left|\phi_{\mathrm{m}}\right|$ ocorreram durante a fase de florescimento e frutificação (a partir de 74 DAT), comprovando que a maior demanda de água requerida pela cultura ocorre durante essas fases. Em solos arenosos cultivados com hortaliças, Carrijo et al. (1999) recomendam, para um bom desenvolvimento das culturas, a manutenção de potencial mátrico na faixa de -150 a $-100 \mathrm{~cm}$.c.a. Considerando-se esta constatação, diz-se que o manejo da irrigação proporcionou a manutenção da umidade, suficiente para se atender à demanda hídrica no primeiro ciclo do meloeiro. No que se refere ao segundo ciclo, não se constataram variações entre os níveis de salinidade devido, provavelmente, ao ataque severo de nematóides (Meloidogyne javanica) a partir do período de florescimento, o que reduziu a absorção de água pelas plantas e resultou na menor variação diária do potencial (Dias, 2004).

\section{Consumo de água sob estresse salino}

As lâminas de irrigação aplicadas durante o primeiro ciclo, para os diferentes níveis de salinidade inicial do solo e manejos da fertirrigação, estão apresentadas na Figura 8. Para o manejo tradicional, não se verifica diferença sensível do consumo de água pelo sistema solo-planta entre os níveis de salinidade inicial do solo, mas para o manejo controlado ocorreu redução na lâmina de irrigação acumulada entre os níveis de salinidade, principalmente a partir de 50 DAT. Observa-se, também, que a diferença no consumo entre os níveis de salinidade aumenta com o tempo, registrando-se maior decréscimo nos níveis de maior salinidade $\left(\mathrm{S}_{5}\right.$ e $\left.\mathrm{S}_{6}\right)$. Ressalta-se que a quantidade de água transpirada pela planta nos primeiros dias após o transplantio (0-30 DAT) era, possivelmente, de ordem ínfima, quando comparada com o volume evaporado na superfície do solo, razão pela qual não foi constatada diferença apreciável de consumo, em função da salinidade, no referido período de aplicação.

Com relação ao segundo ciclo, o comportamento foi semelhante ao do primeiro ciclo, no que se refere aos efeitos dos níveis mais salinos na redução do consumo de água pela
A.

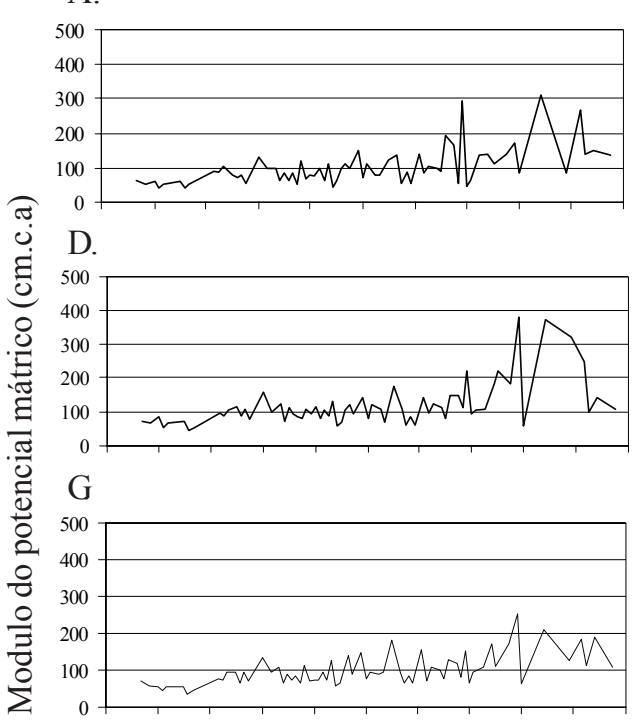

J.

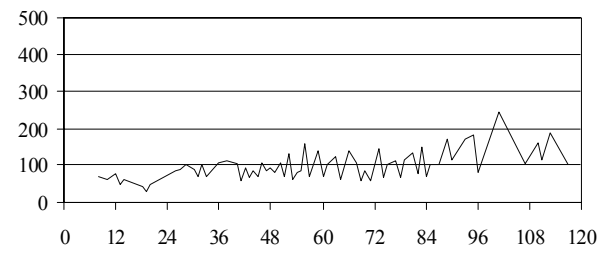

B.

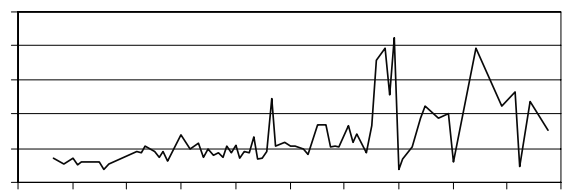

E.

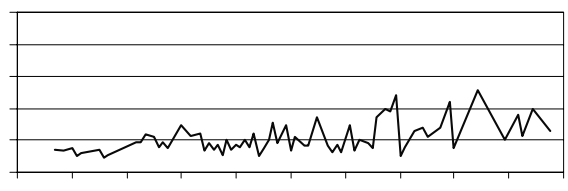

H.

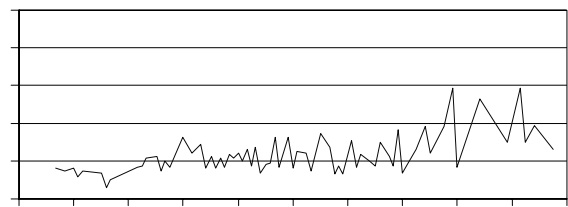

K.

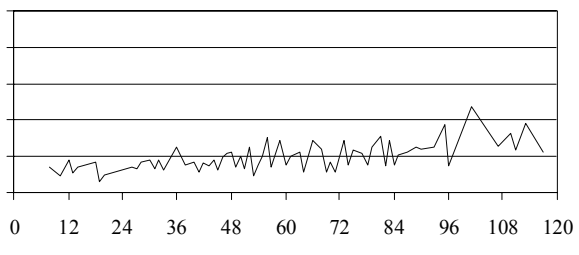

C.

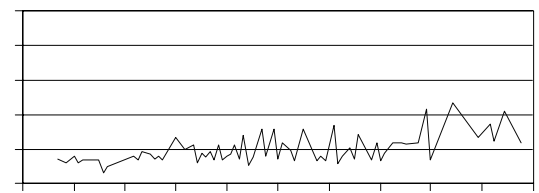

F.

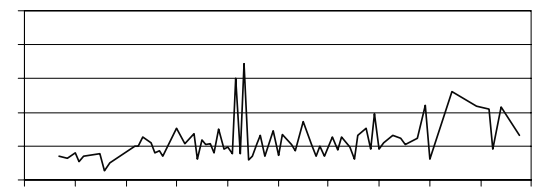

I.

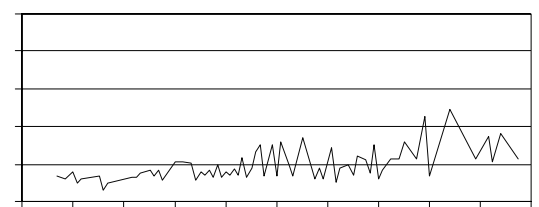

L.

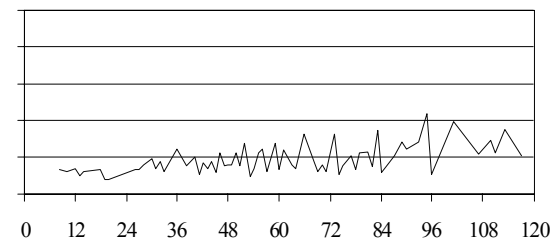

Dias após o plantio

Figura 7. Módulo do potencial mátrico, ao longo do $1^{\circ}$ ciclo, na profundidade de $20 \mathrm{~cm}$ para os tratamentos: $\mathrm{S}_{1} \mathrm{M}_{1}(\mathrm{~A}), \mathrm{S}_{1} \mathrm{M}_{2}(\mathrm{~B})$, $\mathrm{S}_{2} \mathrm{M}_{1}(\mathrm{C}), \mathrm{S}_{2} \mathrm{M}_{2}(\mathrm{D}), \mathrm{S}_{3} \mathrm{M}_{1}(\mathrm{E}), \mathrm{S}_{3} \mathrm{M}_{2}(\mathrm{~F}), \mathrm{S}_{4} \mathrm{M}_{1}(\mathrm{G}) \mathrm{e} \mathrm{S}_{4} \mathrm{M}_{2}(\mathrm{H}), \mathrm{S}_{5} \mathrm{M}_{1}(\mathrm{I}), \mathrm{S}_{5} \mathrm{M}_{2}(\mathrm{~J}), \mathrm{S}_{6} \mathrm{M}_{1}(\mathrm{~L})$ e $\mathrm{S}_{6} \mathrm{M}_{2}(\mathrm{M})$ 


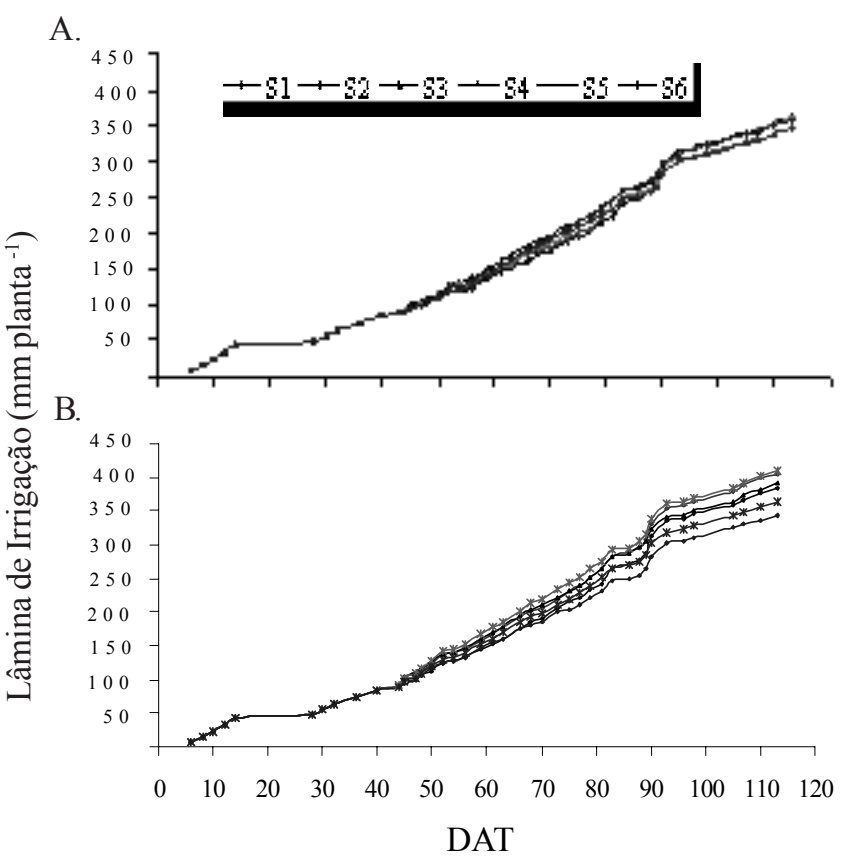

Figura 8. Lâmina de água acumulada aplicada na irrigação durante o primeiro ciclo da cultura do melão, para o manejo tradicional - $M_{1}(A)$ e manejo controlado - $M_{2}$ (B) da fertirrigação

planta, embora com menores lâminas de água diárias e acumuladas aplicadas por irrigação durante as diferentes épocas (Figura 9). De acordo com Rhoades \& Loveday (1990) a concentração de sais solúveis na zona radicular reduz o fluxo de água no sentido solo-planta-atmosfera, devido ao efeito osmótico na planta.

No manejo controlado, a diferença no consumo de água entre os níveis de salinidade é mais evidenciada em virtude, provavelmente da manutenção do mesmo nível de salinidade do solo na zona radicular até o final do ciclo.

As equações de regressão relativas ao consumo total de água em função do nível de salinidade do solo, ao final dos dois ciclos consecutivos do meloeiro, estão dispostas na Figura 10. No manejo tradicional não foi bom o ajuste entre o consumo de água e os níveis de salinidade iniciais do solo, nos dois ciclos do meloeiro; já no manejo controlado da fertirrigação, verificou-se efeito quadrático significativo dos níveis de salinidade sobre o consumo da planta, com decréscimo no consumo hídrico a partir da $\mathrm{CE}_{\mathrm{es}}=2,76 \mathrm{dS} \mathrm{m}^{-1}\left(\mathrm{R}^{2}=0,84\right) \mathrm{e} \mathrm{da}$ $\mathrm{CE}_{\mathrm{es}}=1,74 \mathrm{dS} \mathrm{m}^{-1}\left(\mathrm{R}^{2}=0,64\right)$, para os primeiro e segundo ciclos, respectivamente, indicando que as plantas podem ter sofrido algum estresse hídrico induzido pelo estresse salino (seca fisiológica).

O efeito quadrático observado no consumo hídrico foi semelhante aos efeitos encontrados para as variáveis de crescimento da planta (altura e área foliar), comprovando que o estresse salino induz ao menor consumo de água, como conseqüência da redução do crescimento. Resultados idênticos também foram apresentados por Hoffman (1985), Medeiros (1998), Soares (2001) e Silva (2002), os quais demonstraram que a redução relativa à evapotranspiração das plantas submetidas ao estresse salino, se correlaciona com a diminuição de biomassa.

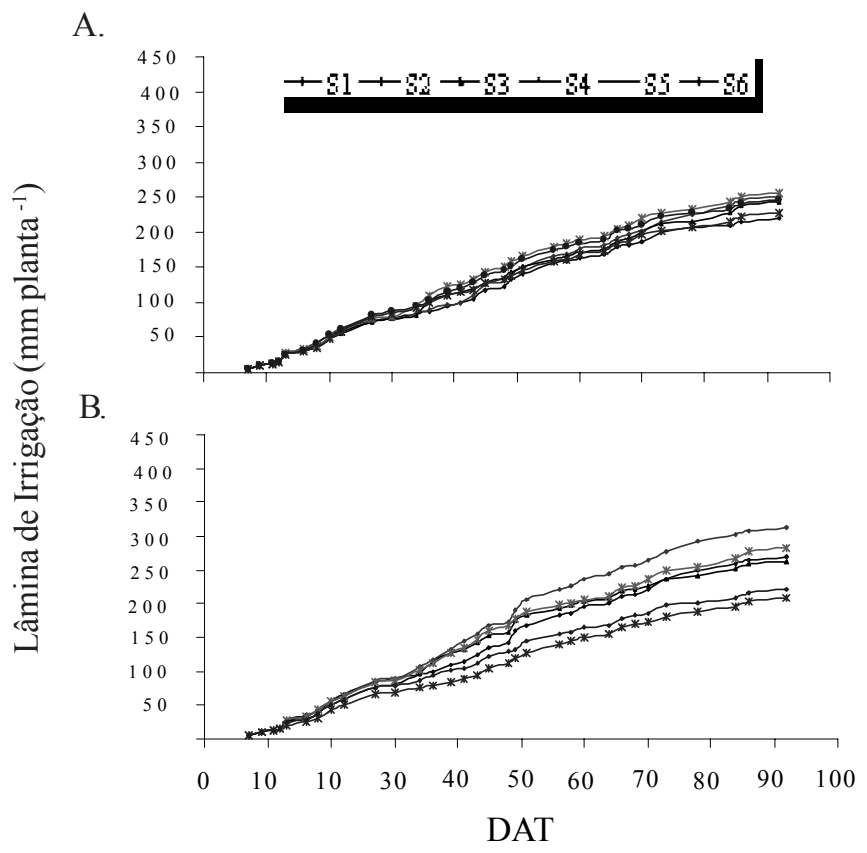

Figura 9. Lâmina de água acumulada aplicada na irrigação durante o segundo ciclo da cultura do melão para o manejo tradicional - $\mathrm{M}_{1}(\mathrm{~A})$ e manejo controlado $-\mathrm{M}_{2}(\mathrm{~B})$ da fertirrigação

A.

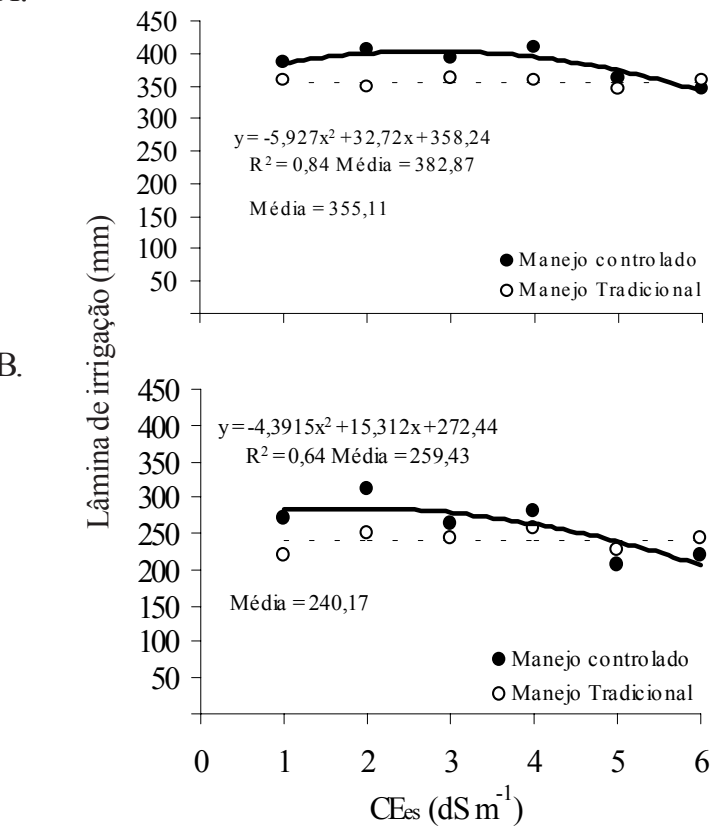

Figura 10. Lâmina de água aplicada na irrigação em função dos níveis de salinidade para os primeiro (A) e segundo (B) ciclos

Segundo Doorenbos \& Kassam (1994), existe uma relação direta entre a evapotranspiração e o crescimento, ou seja, a evapotranspiração é máxima, e da mesma forma o crescimento, quando a necessidade hídrica da planta é plenamente satisfeita; de modo inverso, quando existe uma restrição hídrica ocorre também redução do crescimento, fato constatado no presente estudo, pois o aumento da $\mathrm{CE}_{\mathrm{es}}$ reduziu o consumo de água pelas plantas, a partir de determinado nível. 


\section{CONCLUSÕES}

1. É possível, com auxílio dos extratores de solução por cápsulas porosas, monitorar a concentração total de sais na solução do solo e manter a salinidade em nível desejado, controlando a condutividade elétrica da solução extraída.

2. Os maiores níveis de salinidade ocorreram na região próxima à superfície do solo e abaixo do gotejador, diminuindo com a profundidade; ao longo do ciclo verificou-se alargamento do bulbo salino aumentando, assim, a área de atuação dos sais na região radicular.

3. Ocorreu diferença no consumo de água entre os diferentes níveis de salinidade e esta foi mais evidenciada no manejo controlado da fertirrigação.

4. A obtenção da $\mathrm{CE}_{\mathrm{es}}$ por meio da correção da umidade a partir dos valores de $\mathrm{CE}_{1: 2}$, acarreta superestimativas do seu valor, devido à maior solubilização dos sais nas soluções de extratos mais diluídos; já o método de estimativa da $\mathrm{CE}_{\mathrm{es}}$ a partir da CE com extratores de solução, mostrou-se preciso e simples para avaliar a salinização dos solos, causada por excesso de adubos

\section{LITERATURA CITADA}

Ayers, R.S.; Westcot, D.W. Qualidade da água na agricultura. Campina Grande: UFPB, 1991. 218p. FAO. Estudos de Irrigação e Drenagem, 29

Blanco, F.F. Tolerância do pepino enxertado à salinidade em ambiente protegido e controle da salinização do solo. Piracicaba: ESALQ, 1999, 104p. Dissertação Mestrado

Burgueño, $\mathrm{H}$. La fertirrigación en cultivos hortícolas com acolchado plástico. Culiacán: BURSAR, 1996. v.1, 45p.

Carrijo, O.A.; Marouelli, W.A.; Silva, H.R. Manejo da água na produção de hortaliças em cultivo protegido. Informe Agropecuário, Belo Horizonte, v.20, n.200/201, p.45-51, 1999.

Daker, A. Irrigação e drenagem. A água na agricultura. 2.ed. Rio de Janeiro: Freitas Bastos, 1984. 543p.

Dias, N.S. Evolução da salinidade de um Luvissolo cultivado com melão irrigado por gotejamento. Campina Grande: UFCG, 2001. 72p. Dissertação Mestrado

Dias, N.S. Manejo da fertirrigação e controle da salinidade em solo cultivado com melão rendilhado sob ambiente protegido. Piracicaba: ESALQ, 2004. 110p. Tese Doutorado

Dias, N.S.; Duarte, S.N.; Santos, M.A.L. dos. Ajuste de curvas artificiais de salinização do solo por aplicação excessiva de fertilizantes. In: CONBRAFERT - Congresso Brasileiro de Fertirrigação, 1, 2003, João Pessoa. Resumo...João Pessoa: 2003. CD Rom

Doorenbos, J.; Kassam, A.H. Efeitos da água no rendimento das culturas. Campina Grande: UFPB, 1994. 212 p. Estudos FAO: Irrigação e Drenagem, 33

Filgueira, H.J.A.; Souto, J.S. Avaliação de quatro níveis de relação solo: água para caracterização da condutividade elétrica em solos da região de Patos, PB. In: Reunião Brasileira de Fertilidade do Solo e Nutrição de Plantas, 22, 1995, Manaus. Anais... SBCS, 1995. p.282-283.
Hoffman, G.J. Evapotranspiration in saline soils. In: National conference on advances in evapotranspiration, Chicago, 1985. Proceedings... St. Joseph: ASAE, 1985. p.35-42.

Hoffman, G.J.; Howell, T.A.; Solomon, K.H. Management farm irrigation systems. St. Joseph: ASAE, 1992. 1040p. ASAE Monograph, 9

Hoorn, J.W.; Alphen, J.G. Salt movement, leaching efficiency and leaching requirement. Agricultural and Water Management, Amsterdam, v.4, n.2 p.409-428, 1981.

Hoorn, J.W.; Alphen, J.G. Salinity control. In: Ritzema, H.P. (ed.). Drainage principles and applications. Wageningen: ILRI, 1994. p.533-600. Publication, 16

Kano, C. Extrações de nutrientes pelo meloeiro rendilhado cultivado em ambiente protegido com a adição de potássio e $\mathrm{CO}_{2}$ na água de irrigação. Piracicaba: ESALQ, 2002. 115p. Dissertação Mestrado

Khan, A.A.; Yitayew, M.; Warrick, A.W. Field evaluation of water and solute distribution from a point source. Journal of Irrigation and Drainage Engineering, New York, v.122, n.4, p.221-227, 1996.

Medeiros, J.F de. Manejo da água de irrigação salina em estufa cultivada com pimentão. Piracicaba: ESALQ, 1998. 152p. Tese Doutorado

Medeiros, J.F. de; Cruciani, E.D.; Folegatti, M.V. Manejo, monitoramento e controle da salinidade em áreas de estufa. Piracicaba: ESALQ/DER, 1996.28p.

Oliveira, A.S.; Salati, E. Um estudo sobre as águas subterrâneas da região de Piracicaba. Anais da Escola Superior de Agricultura “Luiz de Queiroz", Piracicaba, v.38, p.163-190, 1981.

Padilla, W.A. Lo que usted saber del suelo su análisis e interpretación para fertirrigación. Quito: Universidad Agraria del Ecuador, 1998. 121p.

Papadopoulos, I. Fertirrigação: situação atual e perspectivas para o futuro. In: Folegatti, M.V. (ed.) Fertirrigação: citrus, flores, hortaliças. Guaíba: Agropecuária, 1999. p.11-84.

Rhoades, J.D. Eletrical conductivity methods for measuring and mapping soil salinity. Advances in Agronomy, San Diego, v.49, n.1, p.201-251, 1994.

Rhoades, J.D.; Loveday, J. Salinity in irrigated agriculture. In: Stewart, D.R.; Nielsen, D.R. (ed.) Irrigation of agricultural crops. Madison: ASA, CSSA, SSSA, 1990. p.1089-1142. Agronomy, 30

Rhoades, J.D.; Miyamoto, S. Testing soils for salinity and sodicity. In: Westerman, R.L. (ed.) Soil testing and plant analysis. 3.ed. Madison: SSSA., 1990. cap. 12, p.299-336. SSSA Book Series, 3

Richards, L.A. Diagnosis and improvement of saline and alkali soils. Washington: United States Departament of Agriculture, 1954. 160p. Agriculture Handbook, 60

Silva, E.F.F. Manejo da fertirrigação e controle da salinidade na cultura do pimentão utilizando extratores de solução do solo. Piracicaba: ESALQ, 2002. 136p. Tese Doutorado

Silva, E.F.F; Duarte, S.N.; Coelho, R.D. Salinização dos solos cultivados sob ambiente protegidos no Estado de São Paulo. In: Folegatti, M.V. (ed.) Fertirrigação: citrus, flores e hortaliças. Guaíba: Agropecuária, 1999. p.267-277.

Soares, A.J. Efeito de três lâminas de irrigação e de quatro doses de potássio via fertirrigação no meloeiro em ambiente protegido. Piracicaba: ESALQ, 2001. 63p. Dissertação Mestrado 